\title{
Production of 2,3-butanediol in Saccharomyces cerevisiae by in silico aided metabolic engineering
}

\author{
Chiam Yu Ng${ }^{1}$, Moo-young Jung ${ }^{1}$, Jinwon Lee ${ }^{2}$ and Min-Kyu Oh*
}

\begin{abstract}
Background: 2,3-Butanediol is a chemical compound of increasing interest due to its wide applications. It can be synthesized via mixed acid fermentation of pathogenic bacteria such as Enterobacter aerogenes and Klebsiella oxytoca. The non-pathogenic Saccharomyces cerevisiae possesses three different 2,3-butanediol biosynthetic pathways, but produces minute amount of 2,3-butanediol. Hence, we attempted to engineer $S$. cerevisiae strain to enhance 2,3-butanediol production.
\end{abstract}

Results: We first identified gene deletion strategy by performing in silico genome-scale metabolic analysis. Based on the best in silico strategy, in which disruption of alcohol dehydrogenase (ADH) pathway is required, we then constructed gene deletion mutant strains and performed batch cultivation of the strains. Deletion of three ADH genes, $A D H 1, A D H 3$ and $A D H 5$, increased 2,3-butanediol production by 55-fold under microaerobic condition. However, overproduction of glycerol was observed in this triple deletion strain. Additional rational design to reduce glycerol production by GPD2 deletion altered the carbon fluxes back to ethanol and significantly reduced 2,3butanediol production. Deletion of ALD6 reduced acetate production in strains lacking major ADH isozymes, but it did not favor 2,3-butanediol production. Finally, we introduced 2,3-butanediol biosynthetic pathway from Bacillus subtilis and $E$. aerogenes to the engineered strain and successfully increased titer and yield. Highest 2,3-butanediol titer $\left(2.29 \mathrm{~g} \cdot \cdot^{-1}\right)$ and yield $\left(0.113 \mathrm{~g} \cdot \mathrm{g}^{-1}\right)$ were achieved by $\Delta a d h 1 \Delta a d h 3 \Delta a d h 5$ strain under anaerobic condition.

Conclusions: With the aid of in silico metabolic engineering, we have successfully designed and constructed $S$. cerevisiae strains with improved 2,3-butanediol production.

Keywords: 2,3-Butanediol, Saccharomyces cerevisiae, Metabolic engineering, Flux balance analysis, Alcohol dehydrogenase, OptKnock

\section{Background}

With soaring oil price but indefinitely high demand for petroleum, various sustainable forms of alternative energy and chemicals have been sought after. Microorganisms are able to utilize a wide range of substrate such as plant biomass or agricultural waste and convert them into valuable chemicals and biofuel. With rapid development in microbial engineering technology, this bio-based refinery will be more feasible in terms of cost in the future and eventually reduce the dependency on fossil fuel.

2,3-Butanediol is an interesting metabolic product as its derivatives can be used in wide arrays of industries ranging from synthetic rubber, solvents and drugs. 2,3-

\footnotetext{
* Correspondence: mkoh@korea.ac.kr

${ }^{1}$ Department of Chemical \& Biological Engineering, Korea University, Seoul

136-701, Republic of Korea

Full list of author information is available at the end of the article
}

Butanediol can be produced efficiently via mixed acid fermentation with prokaryotes such as Klebsiella pneumonia, Klebsiella oxytoca, Enterobacter aerogenes, Serratia, and Bacillus polymyxa [1]. In these bacteria, pyruvate is first converted into $\alpha$-acetolactate by acetolactate synthase. In anoxic state, $\alpha$-acetolactate decarboxylase catalyzes the conversion of $\alpha$-acetolactate into acetoin (Figure 1, green arrow). In the presence of oxygen, spontaneous decarboxylation of $\alpha$-acetolactate produces diacetyl. Diacetyl reductase then converts diacetyl into acetoin. 2,3-Butanediol is resulted from the reduction of acetoin by butanediol dehydrogenase.

Most of these bacteria, however, belong to class 2 microorganisms, which are not desirable in industrialscale fermentation in terms of safety regulations [2]. The need for safe 2,3-butanediol producers are undeniably important when 2,3-butanediol are used as precursors

\section{Biomed Central}




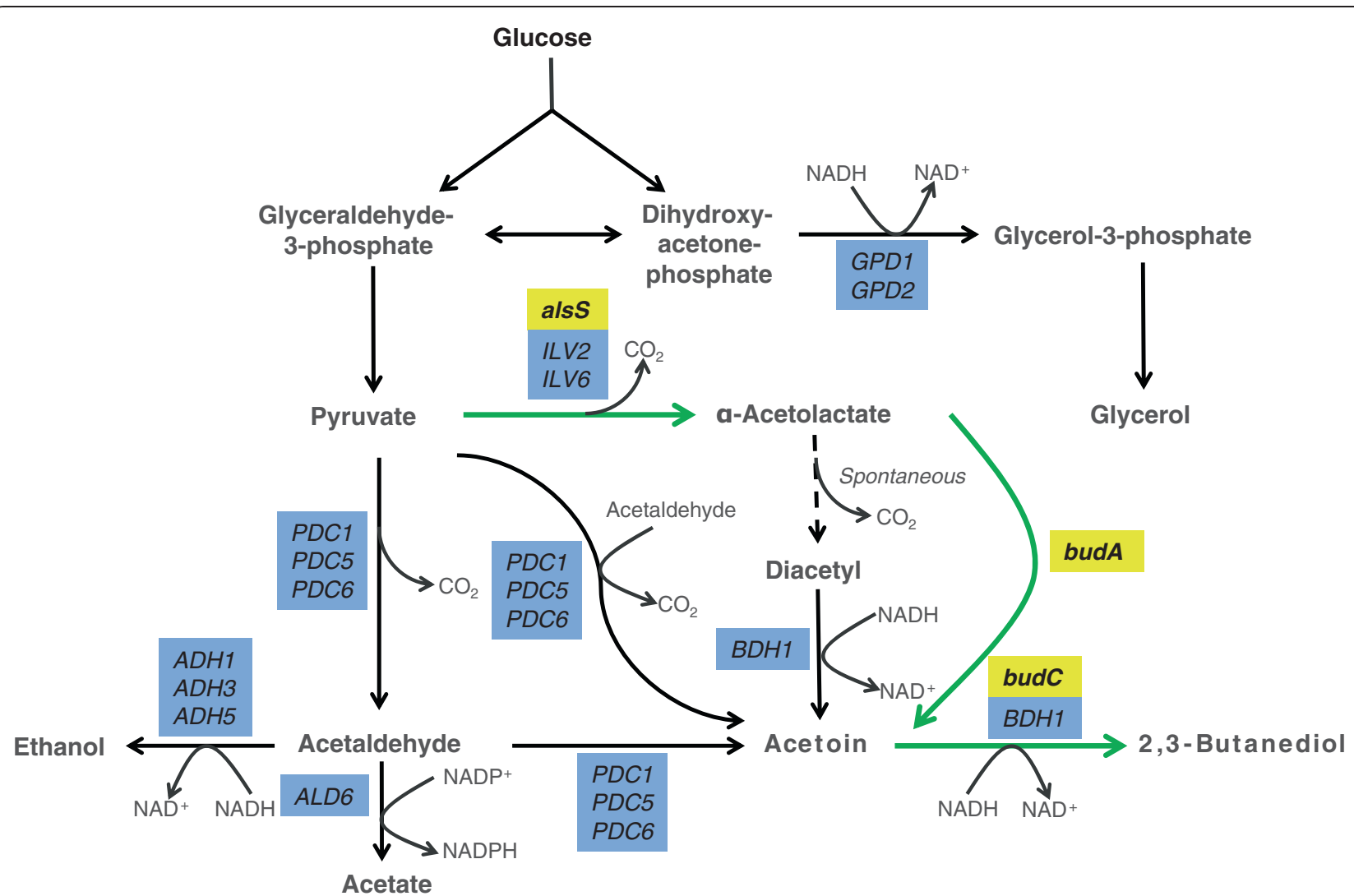

Figure 1 Metabolic pathways for 2,3-butanediol biosynthesis and pyruvate metabolism in S. cerevisiae. Green arrow shows the bacterial 2,3-butanediol synthesis pathway through a-acetolactate decarboxylase. Blue boxes contain the S. cerevisiae innate genes, while yellow boxes indicate the foreign genes introduced to the engineered strains.

for food additives and cosmetics. Yang et al. has successfully screened a GRAS (generally regarded as safe) microorganism Bacillus amyloliquefaciens B10-127 that has high yield (0.42 $\mathrm{g} \cdot \mathrm{g}^{-1}$ glucose) and could produce up to $92.3 \mathrm{~g} \cdot \mathrm{l}^{-1}$ of 2,3-butanediol during fed-batch fermentation [3]. The model eukaryotic microorganism Saccharomyces cerevisiae which is widely used in the industry is also a promising host microorganism.

In $S$. cerevisiae, acetaldehyde, pyruvate and $\alpha$ acetolactate are the precursors of 2,3-butanediol (Figure 1). The biosynthetic pathway with diacetyl as intermediate is similar with that of the bacteria's. However, $\alpha$ acetolactate decarboxylase is not found in most of the S. cerevisiae strain. Instead, $S$. cerevisiae can synthesize acetoin via the condensation of active acetaldehyde with acetaldehyde by pyruvate decarboxylase [4]. In addition, the carboligase mechanism of pyruvate decarboxylase for the synthesis of acetoin from the reaction between pyruvate and acetaldehyde has been elucidated previously [5]. Acetoin is then converted into 2,3-butanediol by butanediol dehydrogenase.

Hitherto, there are few reports regarding 2,3-butanediol production by engineered S. cerevisiae strain. 2,3-
Butanediol production has been favored over acetoin and diacetyl in beer and wine fermentation due to its neutral organoleptic characteristics. Diacetyl production in brewing process is undesirable due to its unpleasant flavor and its low taste threshold. Previous attempts successfully reduced the diacetyl production in brewer's yeast by expressing heterologous $\alpha$-acetolactate decarboxylase from Klebsiella terrigena and Enterobacter aerogenes [6,7]. 2,3-Butanediol which has a higher flavor threshold than diacetyl is subsequently produced as the final product. Other than that, overexpression of GPD1 in wine yeast strains also led to increased 2,3-butanediol production [8]. Recently, Ehsani et al. [9] have shown that by the overproduction of native Bdh1p or by changing the coenzyme specificity of $B D H 1$ of a strain that overproduces glycerol and lacks $A L D 6$, they manage to yield $0.0307-0.033 \mathrm{~g} \cdot \mathrm{g}^{-1}$ of 2,3-butanediol in synthetic medium that simulated standard grape juice. Nevertheless, the focus of previous attempts did not target 2,3-butanediol as the main product.

Despite possessing more than two innate pathways that led from pyruvate to 2,3-butanediol [10], the 
productivity is extremely poor in wild-type $S$. cerevisiae strain when compared with bacteria[2]. We believed that the capability of $S$. cerevisiae in producing 2,3-butanediol can be further improved. For this purpose, computational strain design and optimization procedures can guide researcher in seeking for the best metabolic engineering strategy that coupled product formation with cellular objective such as growth [11]. Several genomescale reconstruction models of yeast have been published previously [12-15]. Using these constraint-based stoichiometric models of yeast, we can predict the metabolic flux redistribution in a strain caused by a genetic or an environmental perturbation by flux balance analysis (FBA) methods [16,17].

OptKnock framework[18] was one of the earliest FBA-based algorithms being developed to predict gene deletion strategies for the overproduction of a target chemical while maximizing the cellular objective such as growth. Since then, this algorithm has been successfully applied to design Escherichia coli strain for the overproduction of lactate [19], malonyl-CoA [20] and 1,4-butanediol [21]. In comparison with E. coli stoichiometric models, the eukaryote $S$. cerevisiae models are compartmentalized and more complex in terms of its metabolic network. Constraint-based modeling approach for chemical overproduction in $S$. cerevisiae has been received with mixed opinions [22-24]. Kennedy et al. demonstrated a successful FBA-based design approach for the production of formic acid, a non-fermentative metabolite in yeast [25]. Meanwhile, Bro et al. has applied the genome-scale cell model of $S$. cerevisiae to construct a strain with $40 \%$ reduced glycerol yield and increased ethanol yield [26].

In this paper, we attempted to engineer $S$. cerevisiae strain for the production of 2,3-butanediol. To achieve this objective, in silico strain design was performed with a recently published $S$. cerevisiae genome-scale metabolic model of yeast, iMM904 [13]. OptKnock algorithm identified genes that have to be deleted for the overproduction of 2,3-butanediol. Based on the in silico prediction, we constructed a few strains with different combinations of gene deletions and quantitatively analyzed the extracellular metabolites in batch fermentations. We also evaluated whether two other strategies that would reduce byproducts and increase pre-cursors of 2,3-butanediol will favor its production: 1. deletion of a NADP ${ }^{+}$ dependent aldehyde dehydrogenase encoded by $A L D 6$ and 2. deletion of NADH dependent glycerol-3phosphate (G3P) dehydrogenase encoded by GPD2. Finally, we compared the effect of the amplification of $S$. cerevisiae innate 2,3-butanediol biosynthesis pathway with the introduction of bacterial pathway to different engineered host strains.

\section{Results and discussion}

\section{In silico design of 2,3-butanediol producing strain using} OptKnock

The flux through butanediol dehydrogenase leading to the biosynthesis of R,R-2,3-butanediol was being considered as our bioengineering objective and biomass production as the cellular objective in OptKnock. All simulations were performed under aerobic condition with glucose as the substrate. We could not identify single reaction deletion or double reaction deletion strategy that will yield significant amount of 2,3-butanediol in iMM904 model.

As we proceeded with higher numbers of reactions for deletion, we initially obtained model $\mathrm{C}$ and model D with four and five target reactions respectively (Table 1). Both models include the deletion of pyruvate dehydrogenase $(\mathrm{PDH})$ complex and glutamate dehydrogenase. The former is a mitochondrial multi-protein complex that catalyzes the conversion of pyruvate to acetyl-coA with concomitant generation of $\mathrm{NADH}$ [27]. With the deletion of this reaction, more flux from the pyruvate node could be redistributed towards the bioengineering objective. However, the deletion of $\mathrm{PDH}$ reaction reduces $\mathrm{NADH}$ formation that would favor 2,3-butanediol production. Other than that, the deletion of $\mathrm{PDH}$ complexes required deletion of up to five genes encoding different subunits that formed the complex. The NADPH dependent glutamate dehydrogenase encoded by $G D H 1$ and $G D H 3$ genes is responsible for glutamate biosynthesis and has a vital role in ammonium metabolism in yeast. It has been reported that deletion of GDH1 increased ethanol formation and reduced glycerol formation in wild-type strain but reduced growth [28]. We could not clearly interpret the other reactions predicted in model $C$ and D as they are non-intuitive. Aspartate transaminase is an important enzyme in amino acid metabolism that catalyzes the reversible conversion of aspartate and $\alpha$-ketoglutarate to glutamate and oxaloacetate. NAD kinase is responsible for the phosphorylation of $\mathrm{NAD}^{+}$to $\mathrm{NADP}^{+}$; but the combination of POS5 and UTR1 genes deletion is synthetically lethal [29]. Meanwhile, cytidylate kinase and nucleoside diphosphate kinase are reactions in nucleotide salvage pathway, whereas thymidine phosphorylase is an enzyme in purine and pyrimidine biosynthesis pathway (Additional file 1(a)).

By removing these reactions from the set of target reactions for knockout, we managed to obtain model A. In this model, elimination of all alcohol dehydrogenase $(\mathrm{ADH})$ reactions was proposed. 2,3-Butanediol and ethanol not only share the same precursor molecules, which are pyruvate and acetaldehyde; the conversion of these precursor molecules to 2,3-butanediol and ethanol also require the input of $\mathrm{NADH}$. Thus, removal of the highly 
Table 1 Deletion strategies suggested by OptKnock algorithm for the production of 2,3-butanediol

\begin{tabular}{|c|c|c|c|c|}
\hline ID & $\begin{array}{l}\text { Target reaction } \\
\text { for knockouts* }\end{array}$ & $\begin{array}{l}\text { Corresponding gene(s) } \\
\text { for knockouts }\end{array}$ & $\begin{array}{l}\text { Maximum specific } \\
\text { growth rate }(1 / \mathrm{hr})\end{array}$ & $\begin{array}{l}\mathrm{R}, \mathrm{R}-2,3-B u t a n e d i o l \\
\text { yield (g/g glucose) }\end{array}$ \\
\hline$\overline{W T}$ & - & - & 0.288 & 0 \\
\hline \multirow[t]{3}{*}{ A } & 1. ALCD2ir: & $A D H 1, A D H 4, A D H 5$ & 0.231 & 0.313 \\
\hline & 2. ALCD2irm & $A D H 3$ & & \\
\hline & 3. ALCD2x & SFA1 & & \\
\hline \multirow[t]{4}{*}{ B } & 1. ALCD2ir & $A D H 1, A D H 4, A D H 5$ & 0.190 & 0.362 \\
\hline & 2. ALCD2x & SFA1 & & \\
\hline & 3. GTPCI & FOL2 & & \\
\hline & 4. $\mathrm{MDH}$ & $\mathrm{MDH} 2$ & & \\
\hline \multirow[t]{4}{*}{ C } & 1. GLUDyi & GDH1, GDH3 & 0.266 & 0.151 \\
\hline & 2. NADK & UTR1, UTR2, POS5 & & \\
\hline & 3. NDPK3 & YNK1 & & \\
\hline & 4. $\mathrm{PDHm}$ & $\begin{array}{l}\text { PDB1, PDA1, LAT1, } \\
\angle P D 1, P D X 1\end{array}$ & & \\
\hline \multirow[t]{5}{*}{ D } & 1. ASPTA & AAT2 & 0.264 & 0.151 \\
\hline & 2. CYTK1 & - & & \\
\hline & 3. GLUDyi & GDH1, GDH3 & & \\
\hline & 4. $\mathrm{PDHm}$ & $\begin{array}{l}P D B 1, P D A 1, \angle A T 1, \\
\angle P D 1, P D X 1\end{array}$ & & \\
\hline & 5. TMDPP & PNP1 & & \\
\hline
\end{tabular}

* Additional descriptions are provided in Additional file 1.

The maximum specific growth rate and R,R-2,3-butanediol yield were calculated based on $10 \mathrm{mmol} \cdot \mathrm{gDCW}^{-1} \cdot \mathrm{hr}^{-1}$ of glucose uptake. WT stands for the complete network of iMM904 model.

active alcoholic fermentation pathway of $S$. cerevisiae may favor the production of 2,3-butanediol by increasing the supply of pyruvate, acetaldehyde and NADH. Even though this strain has a growth rate $20 \%$ lower than that of the reference strain, it is predicted to yield $0.313 \mathrm{~g} \cdot \mathrm{g}^{-1}$ glucose of 2,3-butanediol (Additional file 1(b)).

Another quadruple deletion mutant strain with $15 \%$ higher yield of 2,3-butanediol was also proposed as a solution. In addition to the cytosolic ADH reaction of model A, cytosolic malate dehydrogenase $(M D H 2)$, which converts malate to oxaloacetate with a concomitant reduction of $\mathrm{NAD}^{+}$, was suggested as a target reaction. This gluconeogenic reaction is subject to glucose repression. However, during simulation with iMM904 model, this flux showed negative value for glucose grown wild-type strain, suggesting that the opposite reaction is active. OptKnock might have suggested the deletion of this reaction, which competes for NADH with 2,3-butanediol. The reason for GTP cyclohydrolase deletion is unknown. Furthermore, this quadruple deletion mutant has a growth rate equal to $66 \%$ of the reference strain.

Due to the large number of reactions in the genome scale metabolic model, computational strain design with OptKnock produced some non-intuitive deletion strategies that are difficult for logical interpretation. Though, OptKnock has predicted the deletion of PDH and ADH reactions, which are highly competitive for the carbon flux to 2,3-butanediol, as our strain design strategies. Since model A and model B have higher 2,3-butanediol yields than model $\mathrm{C}$ and model $\mathrm{D}$ (Table 1 ), we decided to evaluate the deletion of the $\mathrm{ADH}$ reaction that is required in both model $\mathrm{A}$ and model $\mathrm{B}$.

\section{Strain construction and microaerobic fermentations}

To test this hypothesis provided by OptKnock, we would have to delete all the genes that are responsible for the conversion of acetaldehyde to ethanol. A total of four $\mathrm{ADH}$ genes, $A D H 1, A D H 3, A D H 4$ and $A D H 5$, along with $S F A 1$ gene have to be disrupted. Previous report [30] showed that $A D H 4$ gene product does not contribute to ethanol production. Meanwhile, SFA1 is known as a long-chain ADH [31] and formaldehyde dehydrogenase [32]. Therefore, our target genes for deletion were reduced to three - $A D H 1, A D H 3$ and $A D H 5$.

To identify the contribution of each gene deletion to 2,3-butanediol yield, we have constructed deletion strains with different combination of the three ADH genes (Table 2). Shake-flask cultivations were then performed with these strains at microaerobic condition. Engineered strains took longer time $(\sim 60 \mathrm{~h})$ to complete fermentation than the wild-type strain $(\sim 40 \mathrm{~h})$. Only up to $0.04 \mathrm{~g} \cdot \mathrm{l}^{-1}$ of 2,3 -butanediol $\left(0.002 \mathrm{~g} \cdot \mathrm{g}^{-1}\right)$ was detected in 
Table 2 S. cerevisiae strains used in this study

\begin{tabular}{|c|c|c|}
\hline Strain & Genotype & Reference \\
\hline BY4742 & MATa his $3 \Delta 1$ leu $2 \Delta 0$ lys $2 \Delta 0$ ura $3 \Delta 0$ & EUROSCARF \\
\hline B2C-a1 & BY4742 $\Delta$ adh1::10XP & This study \\
\hline B2C-a1a3 & BY4742 $\Delta$ adh 1::/oxP $\triangle a d h 3: . / 0 x P$ & This study \\
\hline B2C-a1a5 & BY4742 $\Delta a d h 1:: 10 \times P \Delta a d h 5:: 10 x P$ & This study \\
\hline B2C-a1a3a5 & BY4742 $\Delta a d h 1:$ :IoxP $\Delta a d h 5:: 10 x P \Delta a d h 3: . /$ oxP & This study \\
\hline B2C-a1a6 & BY4742 $\triangle$ adh 1::10xP $\triangle$ ald6::IoxP & This study \\
\hline B2C-a1a3a6 & BY4742 $\Delta a d h 1:: 10 x P \Delta a l d 6:: 10 x P \Delta a d h 3:: 10 x P$ & This study \\
\hline B2C-a1a5a6 & BY4742 $\Delta a d h 1:: 10 x P \Delta a l d 6: 10 x P \Delta$ adh5::/oxP & This study \\
\hline$B 2 C-a 1 a 6 g 2$ & BY4742 $\Delta a d h 1:: 10 x P \Delta a l d 6:: 10 x P \Delta g p d 2:$ /oxP & This study \\
\hline B2C-a1a3a5a6g2 & BY4742 $\Delta a d h 1:$ :IoxP $\Delta a$ ald6::IoxP $\Delta g p d 2::$ IoxP $\Delta a d h 3:: 10 x P \Delta$ adh5::IoxP & This study \\
\hline$B 2 C-S B$ & BY4742 p423GPD-BDH1 & This study \\
\hline$B 2 C-A B C$ & BY4742 p423GPD-budC pCTP-URA::TEF1p-alsS + PGK1p-budA & This study \\
\hline $\mathrm{B} 2 \mathrm{C}-\mathrm{a} 1 \mathrm{a} 5-\mathrm{SB}$ & BY4742 $\Delta$ adh 1::IoxP $\triangle a d h 5: . / 0 x P$ p423TEF-BDH1 & This study \\
\hline $\mathrm{B} 2 \mathrm{C}-\mathrm{a} 1 \mathrm{a} 5-\mathrm{ABC}$ & BY4742 $\Delta$ adh 1::IoxP $\Delta a d h 5:: /$ oxP p423GPD-budC pCTP-URA::TEF1p-alsS + PGK1p-budA & This study \\
\hline B2C-a1a6-SB & BY4742 $\Delta$ adh 1::IoxP $\Delta$ ald6::/oxP p423GPD-BDH1 & This study \\
\hline$B 2 C-a 1 a 6-A B C$ & BY4742 $\Delta$ adh 1::IoxP $\Delta$ ald6::/oxP p423GPD-budC pCTP-URA::TEF1p-alsS + PGK1p-budA & This study \\
\hline
\end{tabular}

${ }^{*}$ Genotype is described in the order of the corresponding genetic manipulations.

the culture of BY4742 wild-type strain. In comparison with the wild-type strain, single deletion of the major $\mathrm{ADH}$ gene $A D H 1$ reduced ethanol yield by almost half and increased 2,3-butanediol yield by up to 20.5-fold, with a 2,3-butanediol maximum titers and product yields of $0.825 \mathrm{~g} \cdot \mathrm{l}^{-1}$ and $0.041 \mathrm{~g} \cdot \mathrm{g}^{-1}$, respectively (Figure 2 and Table 3). The double deletion strains B2C-a1a3 ( $\Delta a d h 1$ $\Delta a d h 3)$ and B2C-a1a5 ( $\Delta a d h 1 \Delta a d h 5)$ produced up to $1.54 \mathrm{~g} \cdot \mathrm{l}^{-1}$ and $1.42 \mathrm{~g} \cdot \mathrm{l}^{-1}$ of 2,3-butanediol, respectively, with a 2,3-butanediol yield of $85 \%-88 \%$ more than the $\triangle a d h 1$ single deletion strain. Strain B2C-a1a3a5, of which three ADH isozymes encoded by $A D H 1, A D H 3$ and ADH5 genes were deleted, achieved the highest 2,3butanediol titer and yield among the engineered strains, up to $1.64 \mathrm{~g} \cdot \mathrm{l}^{-1}$ and $0.093 \mathrm{~g} \cdot \mathrm{g}^{-1}$. This triple deletion strain produced $73.3 \%$ lesser ethanol than wild-type strain. Consistent with previous reports [33,34], this strain still retains its ability to produce ethanol due to residual $\mathrm{ADH}$ isozymes. It has higher 2,3-butanediol yield per substrate than strain $\mathrm{B} 2 \mathrm{C}-\mathrm{a} 1 \mathrm{a} 3$ and strain $\mathrm{B} 2 \mathrm{C}$-a1a5 owing to the fact that up to $2.41 \mathrm{~g} \cdot \mathrm{l}^{-1}$ of residual glucose was detected at the end of fermentation.

Previous works stated that acetaldehyde accumulation in $\Delta a d h 1$ strain led to poor growth in glucose $[34,35]$. Acetaldehyde at a level higher than $0.3 \mathrm{~g} \cdot \mathrm{l}^{-1}$ inhibits cell growth [36]. We found that the concentrations of acetaldehyde in the supernatant at the end of fermentation were significantly higher in deletion strains (B2C-a1, $\mathrm{B} 2 \mathrm{C}-\mathrm{a} 1 \mathrm{a} 3, \mathrm{~B} 2 \mathrm{C}-\mathrm{a} 1 \mathrm{a} 5$ and $\mathrm{B} 2 \mathrm{C}-\mathrm{a} 1 \mathrm{a} 3 \mathrm{a} 5)$ than the wildtype strain (Table 3). Accordingly, the final biomass yields for these deletion strains were highly reduced. We also thought that perhaps the high acetaldehyde level in the supernatant, which is toxic to the cells, causes the cessation in glucose uptake of some of the deletion strains. In addition, deletion strains also exhibited 22$71 \%$ higher level of acetate and 6 - 8-fold increase in glycerol level over wild-type strain. Analysis of strain lacking $A D H 1$ or $A D H 1-4$ isozymes previously has shown that glycerol is the main fermentation product for these strains, while acetaldehyde and acetate are produced in significant amounts [30]. This is because reducing the flux towards ethanol led to the accumulation of NADH and acetaldehyde. Generation of glycerol allows the strain to reoxidize excess $\mathrm{NADH}$ in the cytosols, while acetate formation reduces the acetaldehyde accumulated. Nevertheless, 2,3-butanediol production in these strains has not been reported. 2,3-Butanediol can be synthesized directly from pyruvate via yeast innate pathway. Production of 2,3-butanediol requires the oxidation of $\mathrm{NADH}$, whereas oxidation of acetaldehyde to acetate reduced the cofactor $\mathrm{NAD}(\mathrm{P})^{+}$. Thus, accumulation of acetaldehyde in strains $\mathrm{B} 2 \mathrm{C}-\mathrm{a} 1, \mathrm{~B} 2 \mathrm{C}-\mathrm{a} 1 \mathrm{a} 3$ and $\mathrm{B} 2 \mathrm{C}-\mathrm{a} 1 \mathrm{a} 5$ strains greatly increased the production of 2,3-butanediol. The results of additional gene deletion strategies to reduce by-products (acetate and glycerol) and their effect on 2,3-butanediol production are discussed in the next sections.

Production of 2,3-butanediol in the engineered strain mostly occurs through the pathways that are catalyzed by pyruvate decarboxylase. Deletion of PDC1 from $\triangle a d h 1$ background was reported to reduce acetaldehyde production [37]. In our study on $\Delta a d h 1 \Delta p d c 1$ strain, 

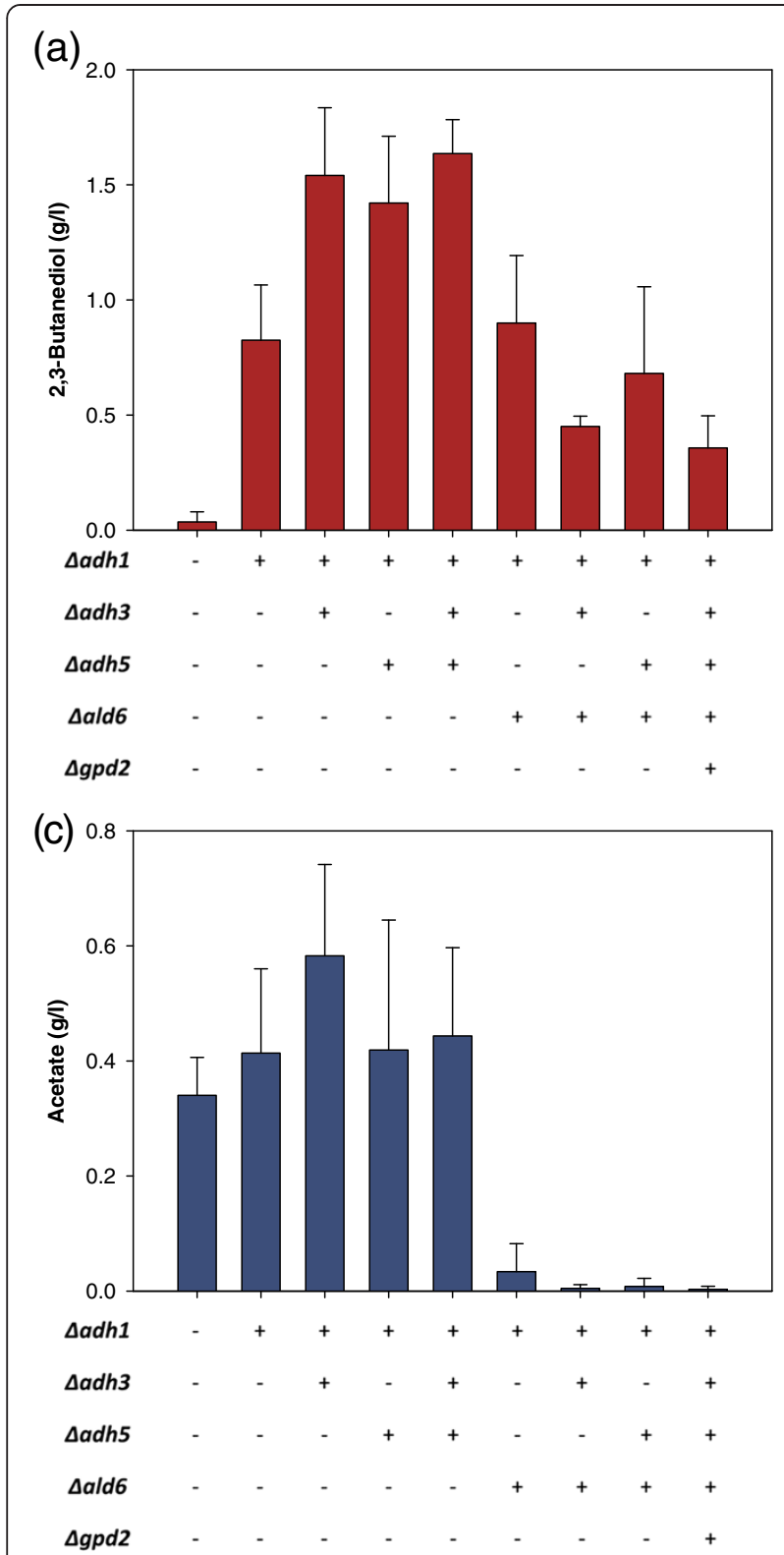

(b)

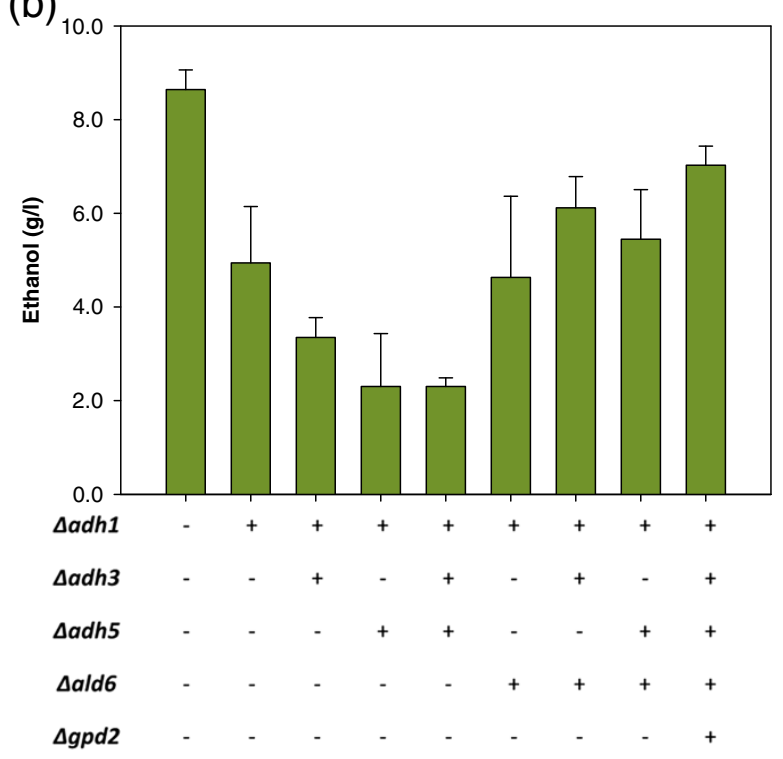

(d)

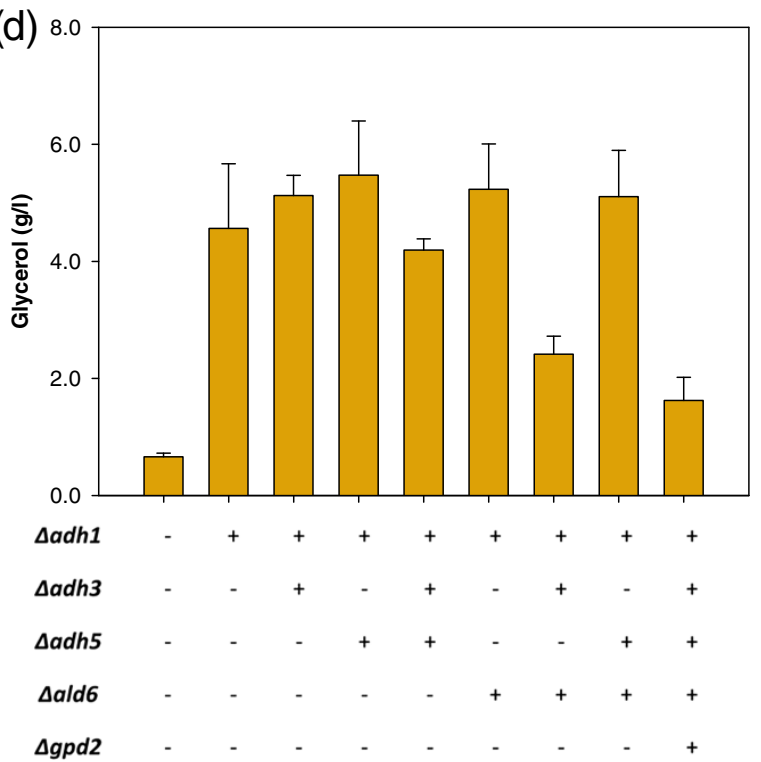

Figure 2 Extracellular metabolite concentrations for batch cultivation. Concentration of (a) 2,3-butanediol, (b) ethanol, (c) acetate and (d) glycerol at the end of batch cultivation under microaerobic conditions. Plus or minus signs indicate presence or absence of the corresponding gene deletion. The first column corresponds to the wild-type strain. Error bars represent standard deviations associated with four independent experiments (except for strains B2C-a1, B2C-a1a5a6, B2C-a1a3a5a6g2, where $\mathrm{n}=3$; and for strains B2C-a1a3a5 and B2C-a1a3a6, where $n=2$ ).

less than $0.60 \mathrm{~g} \cdot \mathrm{l}^{-1}$ of 2,3-butanediol was detected (unpublished observations). Deletion of $P D C 1$ from $\triangle a d h 1$ strain reduced the flux towards acetaldehyde and consequently decreased acetoin production. This attested that pyruvate decarboxylase enzyme is important in the production of acetaldehyde and the production of 2,3butanediol. Nevertheless, the acetoin synthase activity of pyruvate decarboxylase enzyme has been reported to reach saturation level [5] at a very low concentration and increase only by $10 \%$ even with larger pool of acetaldehyde. So, further deletion of more ADH genes did not resulted in a more drastic increase in 2,3-butanediol production.

\section{The effect of ALD6 gene deletion on 2,3-butanediol} production

ALD6 gene encodes the main cytosolic aldehyde dehydrogenase that catalyzes the conversion of acetaldehyde to acetate. Eglinton et al. has shown that acetic acid production can be reduced in glycerol overproducing strain of $S$. cerevisiae by deleting the ALD6 gene [38]. As discussed in the previous section, strains B2C- 
Table 3 Fermentation time, extracellular metabolite concentrations and yields for shake-flask culture under microaerobic condition

\begin{tabular}{|c|c|c|c|c|c|c|c|c|c|}
\hline \multirow[t]{2}{*}{ Strain } & \multirow{2}{*}{$\begin{array}{l}\text { Fermentation } \\
\text { time, hr }\end{array}$} & \multirow{2}{*}{$\begin{array}{l}\text { Dry cell } \\
\text { weight, } \cdot{ }^{-1}\end{array}$} & \multirow{2}{*}{$\begin{array}{l}\text { Residual } \\
\text { glucose, } \mathrm{g} \cdot \mathrm{I}^{-1}\end{array}$} & \multirow{2}{*}{$\begin{array}{l}\text { Acetaldehyde }{ }^{\dagger}, \\
\mathrm{g} \cdot \mathrm{l}^{-1}\end{array}$} & \multicolumn{5}{|c|}{ Yield, $\mathrm{g} \cdot \mathrm{g}^{-1}$ glucose } \\
\hline & & & & & 2,3-Butanediol & Glycerol & Ethanol & Acetoin & Acetate \\
\hline BY4742 & 40 & 1.349 & 0 & 0.118 & 0.002 & 0.032 & 0.417 & 0 & 0.017 \\
\hline $\mathrm{B} 2 \mathrm{C}-\mathrm{a} 1^{*}$ & 56 & 0.787 & 0 & 0.663 & 0.041 & 0.225 & 0.243 & 0.016 & 0.02 \\
\hline B2C-a1a3 & 54 & 0.876 & 0 & 1.194 & 0.076 & 0.254 & 0.166 & 0.012 & 0.029 \\
\hline B2C-a1a5 & 72 & 0.634 & 1.80 & 1.106 & 0.079 & 0.295 & 0.123 & 0.010 & 0.024 \\
\hline B2C-a1a3a $5^{+}$ & 54 & 0.900 & 2.41 & 1.316 & 0.093 & 0.238 & 0.131 & 0.008 & 0.025 \\
\hline B2C-a1a6 & 57 & 0.740 & 0.09 & 0.493 & 0.046 & 0.265 & 0.231 & 0.010 & 0.002 \\
\hline $\mathrm{B} 2 \mathrm{C}-\mathrm{a} 1 \mathrm{a} 3 \mathrm{a} 6^{+}$ & 63 & 0.619 & 0.78 & 0.312 & 0.023 & 0.125 & 0.318 & 0.011 & 0 \\
\hline B2C-a1a5a $6^{\ddagger}$ & 54 & 0.842 & 0 & 0.263 & 0.033 & 0.247 & 0.259 & 0.011 & 0 \\
\hline B2C-a1a3a5a6g $2^{*}$ & 64 & 0.806 & 0 & 0.220 & 0.018 & 0.081 & 0.347 & 0.007 & 0 \\
\hline
\end{tabular}

*All cultures were performed with an initial concentration of $20 \mathrm{~g} \cdot \mathrm{l}^{-1}$ of glucose under microaerobic condition. The extracellular metabolite concentrations and yields (g metabolite produced/g glucose consumed) were determined at the time of glucose exhaustion or when the strains ceased to consume glucose. Fermentation time indicates the mean time of the end of fermentation. Residual glucose indicates the amount of glucose detected in the supernatant at the end of fermentation.

** All data correspond to the mean of four independent experiments $(n=4)$ unless indicated. For all data, standard error of the mean is lower than $10 \%$.

* Data correspond to the mean of three independent experiments $(n=3)$.

${ }^{\dagger}$ Data correspond to the mean of two independent experiments $(n=2)$.

a1, B2C-a1a3, B2C-a1a5 and B2C-a1a3a5 produced more acetate when compared to the wild-type strain. High production of acetic acid lowers the $\mathrm{pH}$ of the culture broth and can induce programmed cell death in $S$. cerevisiae cells [39]. So, we investigated the effect of ALD6 deletion on the production of 2,3-butanediol in the engineered strains with deletion in one or more ADH genes.

Deletion of ALD6 significantly reduced the production of acetate in all the engineered strains, from an average of $0.47 \mathrm{~g} \cdot \mathrm{l}^{-1}$ to undetectable level (Figure 2). However, this decrease in acetate did not correspond to the increase in 2,3-butanediol production in most of the engineered strains. Only strain B2C-a1a6 showed a slight increase in 2,3-butanediol yield when compared to its parent strain (B2C-a1), from $0.041 \mathrm{~g} \cdot \mathrm{g}^{-1}$ to $0.046 \mathrm{~g} \cdot \mathrm{g}^{-1}$. On the contrary, the 2,3-butanediol yield of B2C-a1a3a6 was equal to only $30 \%$ of strain B2C-a1a3. Similarly, strain B2C-a1a5a6 had a 58\% lower 2,3-butanediol yield than strain B2C-a1a5 (Table 3).

We had initially anticipated that deletion of the aldehyde dehydrogenase gene, $A L D 6$, in strains that contained one or more deleted ADH genes would lead to the accumulation of acetaldehyde. This acetaldehyde could then be converted to acetoin through pyruvate decarboxylase reaction and consequently improve 2,3butanediol yield. In contrast to our initial hypothesis, strains $\mathrm{B} 2 \mathrm{C}-\mathrm{a} 1 \mathrm{a} 5 \mathrm{a} 6$ and $\mathrm{B} 2 \mathrm{C}-\mathrm{a} 1 \mathrm{a} 3 \mathrm{a} 6$ yielded higher levels of ethanol and lower levels of acetaldehyde than strains $\mathrm{B} 2 \mathrm{C}-\mathrm{a} 1 \mathrm{a} 5$ and $\mathrm{B} 2 \mathrm{C}-\mathrm{a} 1 \mathrm{a} 3$ which harbor the native ALD6 gene. This suggests an increase in the activity of the remaining $\mathrm{ADH}$ isozymes of these mutant strains as a survival mechanism of the cells due to the toxicity of acetaldehyde. These residual ADH isozymes compete more efficiently for acetaldehyde than the acetoinsynthesizing pyruvate decarboxylase, which is another pathway for acetaldehyde detoxification. Similarly, Roustan et al. [40] have reported that the ADH activity of wine yeast increased when acetaldehyde was added to the stationary phase medium of wine fermentation.

\section{The effect of GPD2 gene deletion on extracellular metabolite yields}

In strains carrying deletion of $A D H 1$, excess G3P is produced by G3P dehydrogenase from dihydroxyacetone phosphate while regenerating $\mathrm{NAD}^{+}$. Glycerol is then formed by the dephosphorylation reaction of glycerol-3phosphatase. Two strains (B2C-a1a6 and B2C-a1a3a5) that produced glycerol as the major fermentation product under microaerobic condition were evaluated for the effect of the disruption of G3P dehydrogenase reaction.

GPD1 and GPD2 encode the isozymes of G3P dehydrogenase. It has been shown that the deletion of both genes cease glycerol production in S. cerevisiae cells [41]. Nevertheless, deletion of both genes was lethal in strain $\mathrm{B} 2 \mathrm{C}-\mathrm{a} 1 \mathrm{a} 6$ as the cell lost the ability to re-oxidize excess NADH and produce ATP. Single deletion of the osmoregulated GPD1 in $\Delta a d h 1$ sald6 background has minor effect in the reduction of glycerol production (data not shown). On the contrary, the deletion of GPD2 in strain $\mathrm{B} 2 \mathrm{C}$-a1a6 reduced glycerol production when compared to the double deletion strain (Figure 3). GPD2 activity is affected by redox control. The limitation in NADH re-oxidation ability due to the deletion of $A D H 1$ in strain $\mathrm{B} 2 \mathrm{C}$-a1a6, as well as the low oxygen condition during microaerobic cultivation, contributes to the 


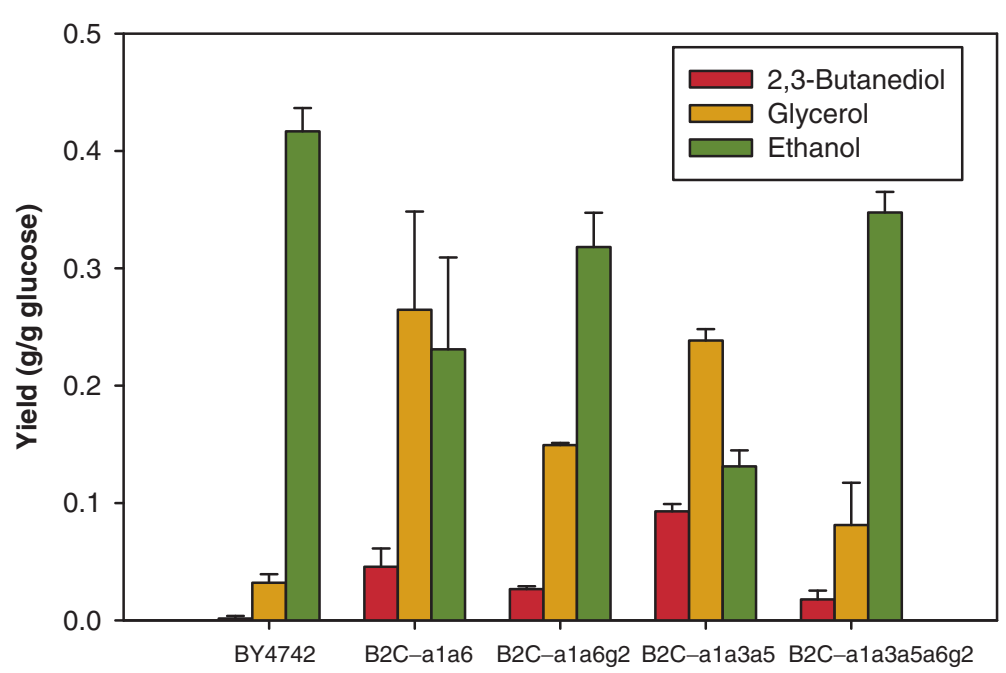

Figure 3 The effect of GPD2 deletion on 2,3-butanediol, glycerol and ethanol yields. Metabolite yields for strains (a) BY4742, (b) B2C-a1a6, (c) B2C-a1a6g2, (d) B2C-a1a3a5 and (e) B2C-a1a3a5a6g2 at the end of batch cultivation under microaerobic condition. Columns and error bars correspond to the mean value and standard deviations of four independent experiments for (a) and (b), duplicate experiments for (c) and (d) and triplicate experiments for (e).

stressful condition where GPD2 expression is highly induced. The increase in pyruvate and NADH due to GPD2 deletion, however, did not favor 2,3-butanediol production in strain $\mathrm{B} 2 \mathrm{C}-\mathrm{a} 1 \mathrm{a} 6 \mathrm{~g} 2$ as ethanol became the major fermentation product. Similarly, deletion of both ALD6 and GPD2 from strain $\mathrm{B} 2 \mathrm{C}-\mathrm{a} 1 \mathrm{a} 3 \mathrm{a} 5$ also completely altered the final product composition of the medium. The quintuple deletion strain displayed lower yield of 2,3-butanediol and glycerol, but higher yield of ethanol (Table 3).

In strains with $A D H 1$ deletion, glycerol is greatly produced to regenerate the reducing equivalents [34]. By reducing the ability of the cells to oxidize excess $\mathrm{NADH}$ through glycerol production, ethanol was again produced as major fermentation product in strains $\mathrm{B} 2 \mathrm{C}-\mathrm{a} 1 \mathrm{a} 6 \mathrm{~g} 2$ and $\mathrm{B} 2 \mathrm{C}-\mathrm{a} 1 \mathrm{a} 3 \mathrm{a} 5 \mathrm{a} 6 \mathrm{~g} 2$. It is possible that the expressions of the remaining $\mathrm{ADH}$ genes were induced to cope with the NADH surplus condition. This is because the synthesis of two moles of ethanol from one mole of pyruvate and one mole of acetaldehyde consumes twice the amount of NADH that is required for the formation of one mole of 2,3-butanediol from the same amount of precursor molecules [40].

\section{Anaerobic batch fermentation}

In order to test whether 2,3-butanediol production can be improved in a highly fermentative condition, strains B2C-a1a5, B2C-a1a6, B2C-a1a3a5 and wild-type strain BY4742 were selected for anaerobic batch cultivation. In the absence of oxygen, S. cerevisiae cells are known to produce significant amount of ethanol and glycerol as a mean to maintain redox balance and generate ATP in the cells. Due to slower growth in anaerobic state, the biomass yield of wild-type and all engineered strains were greatly reduced while the fermentation time increased significantly. All strains exhibited higher glycerol yield due to anaerobiosis. Meanwhile, a decline in the production of the more oxidized acetate was observed in wild-type and the engineered strains (Figure 4).

With deficiency in its $\mathrm{ADH}$ genes, the engineered strains $\mathrm{B} 2 \mathrm{C}-\mathrm{a} 1 \mathrm{a} 5, \mathrm{~B} 2 \mathrm{C}-\mathrm{a} 1 \mathrm{a} 6$ and $\mathrm{B} 2 \mathrm{C}-\mathrm{a} 1 \mathrm{a} 3 \mathrm{a} 5$ produced glycerol as the major fermentation product. Under microaerobic condition, the second major by-product was ethanol, followed by 2,3-butanediol. Interestingly, growth in anoxic state led to the opposite case for strains $\mathrm{B} 2 \mathrm{C}-\mathrm{a} 1 \mathrm{a} 5$ and $\mathrm{B} 2 \mathrm{C}-\mathrm{a} 1 \mathrm{a} 3 \mathrm{a} 5$, where 2,3-butanediol yield was higher than ethanol yield (Figure 4). In comparison to the microaerobic state, the yield of ethanol in anaerobic state was lowered by more than $34 \%$ and $24 \%$ for strains $\mathrm{B} 2 \mathrm{C}-\mathrm{a} 1 \mathrm{a} 5$ and $\mathrm{B} 2 \mathrm{C}-\mathrm{a} 1 \mathrm{a} 3 \mathrm{a} 5$, respectively. Up to $2.29 \mathrm{~g} \cdot \mathrm{l}^{-1}$ of 2,3-butanediol was detected in the fermentation broth for the triple deletion strain, with a yield of $0.113 \mathrm{~g} \cdot \mathrm{g}^{-1}$ (Figure 5). 2,3-Butanediol was not detected in wild-type strain culture broth under anaerobic condition.

An intriguing relationship between the level of oxygen with the production concentration of 2,3-butanediol and ethanol can be deduced from our observation. 2,3Butanediol yield correlates inversely with the level of oxygen and thus the biomass yield. As low oxygen is known to led to higher fermentative energy metabolism in S. cerevisiae, it is not surprising to obtain more 


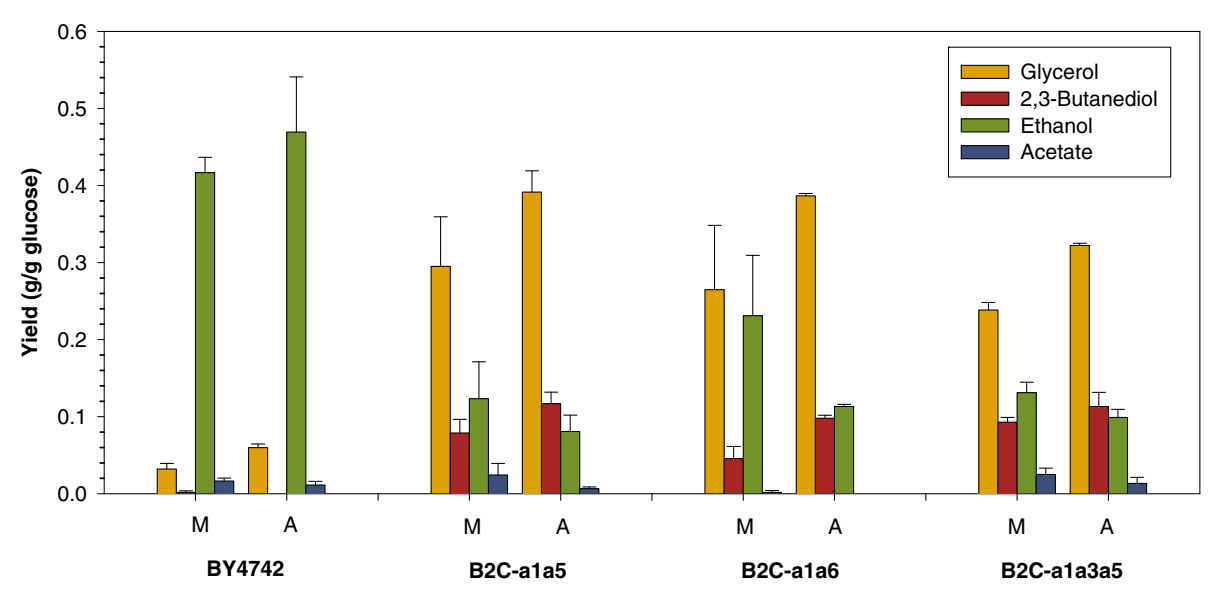

Figure 4 Metabolite profile of cultivation under microaerobic (M) and anaerobic (A) conditions. The bar chart shows glycerol, 2,3butanediol, ethanol and acetate yields for batch fermentation of (a) BY4742, (b) B2C-a1a5, (c) B2C-a1a6 and (d) B2C-a1a3a5 under microaerobic condition and anaerobic condition with $20 \mathrm{~g}^{-l^{-1}}$ of glucose as substrate. Error bars represent standard deviations.

fermentation products under anaerobic condition. It is harder to interpret the connection between 2,3butanediol and ethanol when combined with oxygen level. Since 2,3-butanediol and ethanol shares the same precursor molecule, their concentrations should correlate in an inverse manner. We suspected that the rate of acetaldehyde formation determines the amount of ethanol and 2,3-butanediol produced. However, we could not track the dynamic changes in the concentration of intracellular acetaldehyde in this study.

\section{Improved 2,3-butanediol yield by gene overexpression strategies}

In this section, we compared the single overexpression of innate $B D H 1$ and introduction of additional 2,3-butanediol synthesis pathway from bacteria in three different host: wild-type strain, strain B2C-a1a5 and strain B2Ca1a6. The heterologous pathway was introduced by the co-expression of $B$. subtilis alsS gene, E. aerogenes budA gene and $E$. aerogenes budC gene using two multicopy plasmids (Table 4). We used the acetolactate synthase of

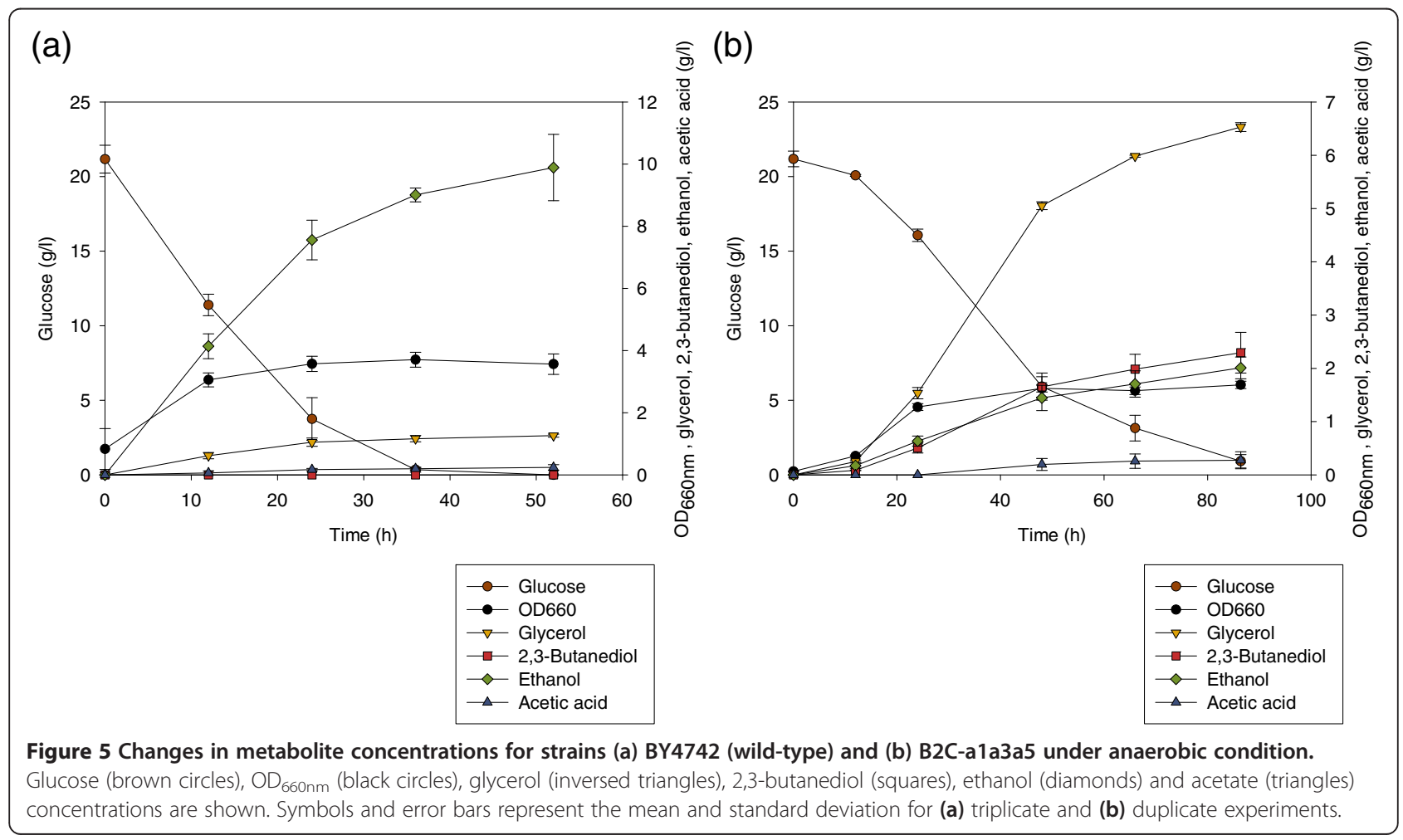


Table 4 Plasmid used in this study

\begin{tabular}{|c|c|c|}
\hline Plasmid & Description & Reference \\
\hline pFA6a-KanMX6 & E. coli kan ${ }^{r}$ gene under the control of Ashbya gossypii TEF promoter-driven & [45] \\
\hline pCNKanMX6 & IoxP flanking KanMX6 at Sall/BamHI and Sacl/EcoRV sites & This study \\
\hline PTKURA3 & loxP flanking S. cerevisiae URA3 gene & This study \\
\hline p423GPD & $2 \mu, H I S 3, P_{G P D 1}$ & [46] \\
\hline p423TEF & $2 \mu, H I S 3, P_{T E F 1}$ & [46] \\
\hline p423GPD-BDH1 & S. cerevisiae BDH1 gene under the control of GPD1 promoter in p423GPD & This study \\
\hline p423TEF-BDH1 & S. cerevisiae BDH1 gene under the control of TEF1 promoter in p423GPD & This study \\
\hline p423GPD-E.a.budC & E. aerogenes KCTC 2190 budC gene under the control of GPD1 promoter in p423GPD & This study \\
\hline pESC-URA & $2 \mu, U R A 3, P_{G A L 10} P_{G A L 1}$ & Stratagene \\
\hline pESC-LEU & $2 \mu, L E U 2, P_{G A L 10} P_{G A L 1}$ & Stratagene \\
\hline pESC-LEU-Cre & P1 bacteriophage Cre recombinase under the control of GAL10 promoter & This study \\
\hline PCTP-URA & $2 \mu$, URA3, $P_{T E F I} P_{P G K 1}$ & This study \\
\hline pCTP-URA::TEF1p-alsS + PGK1p-budA & $\begin{array}{l}\text { Bacillus subtilis alsS gene under the control of TEF1 promoter and E. } \\
\text { aerogenes KCTC } 2190 \text { budA gene under the control of PGK1 promoter in pCTP-URA }\end{array}$ & This study \\
\hline
\end{tabular}

B. subtilis encoded by als $S$ gene because it has stronger preference for pyruvate over 2-ketobutyrate [42]. On the contrary, $S$. cerevisiae native acetolactate synthase encoded by ILV2 has higher affinity for 2-ketobutyrate. $E$. aerogenes budA encodes $\alpha$-acetolactate decarboxylase, which is absent in $S$. cerevisiae strain. The E. aerogenes 2,3-butanediol dehydrogenase, encoded by budC, displays higher affinity for both $\mathrm{NADH}$ and acetoin $\left(\mathrm{K}_{\mathrm{m}}\right.$, $\mathrm{NADH}=5-7 \mu \mathrm{M}$ and $\left.\mathrm{K}_{\mathrm{m} \text {,acetoin }}=0.4 \mathrm{mM}\right)$ than the $S$. cerevisiae native Bdh1p $\left(\mathrm{K}_{\mathrm{m}, \mathrm{NADH}}=45 \mu \mathrm{M}\right.$ and $\mathrm{K}_{\mathrm{m} \text {,acetoin }}=3$ $\mathrm{mM}$ ) [43,44]. The mRNA expression levels of all the genes in the strains we constructed have been confirmed by real-time PCR (data not shown).

In the wild-type strain, overexpression of $B D H 1$ and the bacterial pathway genes increased 2,3-butanediol yield by 2.4-fold and 11.1-fold, respectively (Figure 6). However, the yield of these strains is very low when compared with the deletion strains. The introduction of acetolactate decarboxylase pathway managed to double the yield of 2,3-butanediol in strain B2C-a1a6 to $0.089 \mathrm{~g} \cdot \mathrm{g}^{-1}$. In the engineered strain B2C-a1a5, 2,3-butanediol yield was only slightly affected by the overexpression of endogenous butanediol dehydrogenase gene. The introduction of the heterologous pathway, however, successfully increased 2,3-butanediol yield by $22 \%$ when compared with its parent strain $\mathrm{B} 2 \mathrm{C}-\mathrm{a} 1 \mathrm{a} 5$. Despite the small enhancement of 2,3-butanediol yield, strain $\mathrm{B} 2 \mathrm{C}$-a1a5-ABC produced the highest titer of 2,3-butanediol, with up to $1.67 \mathrm{~g} \cdot \mathrm{l}^{-1}$, corresponding to 2,3-butanediol yield of $0.096 \mathrm{~g} \cdot \mathrm{g}^{-1}$ during microaerobic shake-flask culture.

In wild-type strain and strain $\mathrm{B} 2 \mathrm{C}$-a1a5, overexpression of $B D H 1$ rendered minimal effect on 2,3-butanediol yield. It seems likely that butanediol dehydrogenase reaction is not the bottleneck in 2,3-butanediol biosynthetic pathways in these strains. This is because the flux towards acetoin was probably not adequate in the wildtype strain expressing $B D H 1$; whereas in the case of strain $\mathrm{B} 2 \mathrm{C}-\mathrm{a} 1 \mathrm{a} 5$, it is possible that the conversion of acetaldehyde to acetoin is the rate-limiting step as significant amount of acetaldehyde accumulated in the medium (Table 3). Strain B2C-a1a6 is the only host strain that demonstrated a greater increase in 2,3butanediol yield due the amplification of $B D H 1$. It is also surprising that this strain yielded more 2,3-butanediol than ethanol (0.0887 $\mathrm{g} \cdot \mathrm{g}^{-1}$ and $0.0713 \mathrm{~g} \cdot \mathrm{g}^{-1}$, respectively) when the bacterial pathway genes are introduced. However, this strain (B2C-a1a6-ABC) only managed to

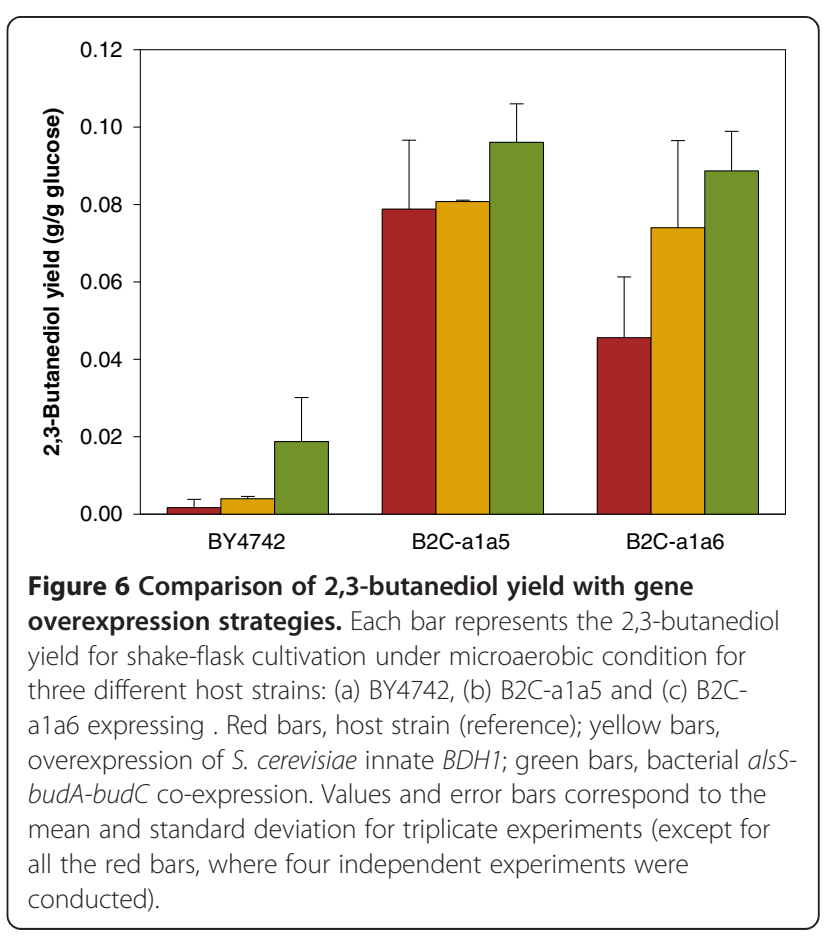


consume half of the amount of glucose supplied in the fermentation medium under microaerobic condition implicating that the cell growth was greatly inhibited by certain metabolites or its cellular redox state is highly imbalanced (Data not shown). To enhance the overall flux from pyruvate to 2,3-butanediol in S. cerevisiae, our data in this section suggests that the overexpression of budC or BDH1 together with alsS and budA can be an alternative to forcing carbon fluxes through the ratelimiting pyruvate decarboxylase pathway.

\section{Conclusions}

In silico S. cerevisiae strain design for the production of 2,3-butanediol suggested the deletion of mitochondrial and cytosolic ADH genes. We thus constructed deletion strains with low ADH activity by the deletion of $A D H 1$, $A D H 3$ and $A D H 5$ genes. Single deletion of major cytosolic $\mathrm{ADH}$ gene $A D H 1$ increased the production titer by around 21-fold. Detoxification mechanism of cells as a response to increased acetaldehyde pool [8], along with the failure to regenerate excess $\mathrm{NADH}$ efficiently through ethanol production stimulate 2,3-butanediol production in the deletion strains. Further reduction of $\mathrm{ADH}$ activity by additional disruption of $A D H 3$ or $A D H 5$ or both genes increased production by $\sim 2$-fold when compared to single deletion strain. But distinctively higher production was not observed, showing that the maximal conversion of acetaldehyde to acetoin and subsequently to 2,3-butanediol has been achieved by reducing ADH activity. High accumulation of acetaldehyde in these deletion strains also implies that the conversion of acetaldehyde to acetoin is rate-limiting. We have thus shown that 2,3-butanediol production can be enhanced in the engineered strains through the introduction of foreign biosynthetic pathway. Further improvement of the conversion efficiency of precursor molecules to 2,3butanediol have to be considered in future study.

OptKnock framework has suggested a deletion strategy that led us to the hypothesis that increase in NADH, acetaldehyde and pyruvate could improve 2,3-butanediol production. This is supported by our data with strains lacking major ADH genes. Nevertheless, this hypothesis is true only to a certain extent as rational deletion strategies based on this hypothesis, including ALD6 deletion to accumulate acetaldehyde and GPD2 deletion to further increase NADH and pyruvate in strains with low ADH activity, did not enhance 2,3-butanediol production but increased ethanol formation instead. Problems remained to be solved to further engineer the industrial workhorse S. cerevisiae for 2,3-butanediol production.

In conclusion, we have demonstrated a successful implementation of in silico guided metabolic engineering approach for the production of a fermentative product in $S$. cerevisiae. 2,3-Butanediol producing $S$. cerevisiae strains were constructed by referring to OptKnock's prediction. Currently, among all the engineered strains, strain B2C-a1a3a5 ( $\Delta a d h 1 \Delta a d h 3 \Delta a d h 5)$ achieved the highest 2,3-butanediol titer and yield under anaerobic condition (2.29 g. $\mathrm{l}^{-1}$ and $\left.0.113 \mathrm{~g} \cdot \mathrm{g}^{-1}\right)$. To our knowledge, this is the first ever report about 2,3-butanediol production in S. cerevisiae strain specifically engineered for its production.

\section{Methods \\ Computational procedure}

FBA-based simulation and strain design using OptKnock algorithm [18] were performed in Matlab R2010a (The MathWorks, Inc., Massachusetts, USA) with the COBRA Toolbox v2.0 [47]. Gurobi Optimizer 4.5 (Gurobi Optimization, Houston, USA) was used to performed linear programming calculations. The recently reported yeast genome-scale model iMM904 [13], consisting of 904 genes, 1577 reactions and 1228 metabolites, was used. All simulations were performed with the following constraints: oxygen uptake rate, $2 \mathrm{mmol}^{-\mathrm{gDCW}^{-}}$ ${ }^{1} \cdot \mathrm{hr}^{-1}$; glucose uptake, $10 \mathrm{mmol} \cdot \mathrm{gDCW}^{-1} \cdot \mathrm{hr}^{-1}$; ATP required for maintenance, $1 \mathrm{mmol} \cdot \mathrm{gDCW}^{-1} \cdot \mathrm{hr}^{-1}$. We excluded all exchange and transports reactions from the target knockouts.

\section{Strains, plasmid and growth conditions}

All engineered strains used in this study are derived from S. cerevisiae BY4742 strain family (BY4742 MATd his $3 \Delta 1$ leu $2 \Delta O$ lys $2 \Delta O$ ura $3 \Delta O$ ). During constructions, strains were grown and maintained on complex (YPD) medium consisting of $1 \%(\mathrm{w} / \mathrm{v})$ bacto yeast extract and $2 \%(\mathrm{w} / \mathrm{v})$ yeast bacto peptone supplemented with $20 \mathrm{~g} \cdot \mathrm{l}^{-1}$ glucose as carbon source. Transformants and strains harboring recombinant plasmid(s) were grown on synthetic complete dropout (SC) medium consisted of $20 \mathrm{~g} \cdot \mathrm{l}^{-1}$ glucose, $6.7 \mathrm{~g} \cdot \mathrm{l}^{-1}$ yeast nitrogen base without amino acid (Difco, BD Biosciences) and the appropriate amino acid supplement mixture (either CSM, CSMURA, CSM-HIS, CSM-LEU or CSM-HIS-URA, MP Biomedicals). In all cases, glucose was autoclaved separately. Escherichia coli DH5 $\alpha$ strain was used for amplification of plasmids. Transformed E. coli DH5 $\alpha$ cells were grown at $37^{\circ} \mathrm{C}$ in Luria-Bertani (LB) medium containing 100ug $\cdot \mathrm{ml}^{-1}$ of ampicillin.

\section{Construction of S. cerevisiae deletion strains}

All the strains used in this work are listed in Table 2. Gene deletion of S. cerevisiae was performed by short flanking homology PCR method with Cre/loxP system for recycling of selection marker gene. pCNKanMX6, a plasmid containing loxP-kanMX-loxP module, were constructed from pFA6a-KanMX6 according to [48]. pTKURA3 were constructed by replacing the KanMX6 
cassette with S. cerevisiae URA3 gene including 200 nucleotides upstream and +77 nucleotides downstream of $U R A 3$ gene. $A D H 1$ gene was deleted by introduction of linearized gene deletion cassette consisting of loxPURA3-loxP sequence flanked by the 45 nucleotides upstream and downstream of $A D H 1$ gene to BY4742 wild-type strain. $A D H 3, A D H 5$ or $A L D 6$ genes were then deleted in $\Delta a d h 1$ background using the same method to construct double gene deletion strains B2C-a1a3, B2Ca1a5 and $\mathrm{B} 2 \mathrm{C}-\mathrm{a} 1 \mathrm{a} 6$. To construct the triple deletion strains $\mathrm{B} 2 \mathrm{C}-\mathrm{a} 1 \mathrm{a} 3 \mathrm{a} 6$ and $\mathrm{B} 2 \mathrm{C}-\mathrm{a} 1 \mathrm{a} 5 \mathrm{a} 6, A D H 3$ and $A D H 5$ were again deleted separately from $\Delta a d h 1 \Delta a l d 6$ background with the previously described method. Meanwhile, strain $\mathrm{B} 2 \mathrm{C}-\mathrm{a} 1 \mathrm{a} 3 \mathrm{a} 5$ was constructed by the deletion of $A D H 3$ from strain B2C-a1a5. Strain B2Ca1a6g2 was constructed by the deletion of GPD2 gene from strain $\mathrm{B} 2 \mathrm{C}$-a1a6. Further deletion of $A D H 3$ and $A D H 5$ genes from strain $\mathrm{B} 2 \mathrm{C}-\mathrm{a} 1 \mathrm{a} 6 \mathrm{~g} 2$ resulted in the quintuple deletion strain $\mathrm{B} 2 \mathrm{C}-\mathrm{a} 1 \mathrm{a} 6 \mathrm{~g} 2 \mathrm{a} 3 \mathrm{a} 5$. All strains were verified by colony polymerase chain reaction (PCR) with appropriate confirmation primers (Additional file 2 ). The aragose gel images of all gene deletion strains are provided (Additional file 3).

\section{Plasmid construction and transformation}

The plasmids used in this study are listed in Table 4. S. cerevisiae $B D H 1$ gene was amplified from the genomic DNA of BY4742 strain with the primers BDH1-FBamHI and BDH1-R-XhoI. The fragment amplified was ligated to p423GPD and p423TEF that were digested with BamHI and XhoI. The resulting construct is p423GPD-BDH1 and p423TEF-BDH1. E. aerogenes budC gene was amplified from the genomic DNA of $E$. aerogenes KCTC 2190 strain by PCR using the primers E.a.budC-F-BamHI and E.a.budC-R-EcoRV. budC gene fragment was then inserted between the BamHI-EcoRV sites of p423GPD, resulting in p423GPD-E.a.budC.

The GAL1/GAL10 promoter regions of pESC-URA (Stratagene) were removed and replaced with the PGK1/ TEF1 divergent promoters by two-step cloning. PGK1 promoter sequence was amplified from the genomic DNA of S. cerevisiae BY4742 wild-type strain with primers PGK1p-F-AatII-NotI and PGK1p-R-BamHI. It was then digested with BamHI and NotI and cloned into pESC-URA to produce pCP-URA. TEF1 promoter region was amplified from $\mathrm{p} 425 \mathrm{TEF}$ with primers TEF1pR-NotI and TEF1p-F-AatII. The TEF1 promoter fragment and pCP-URA were digested by AatII and NotI and then ligated to each other. The new plasmid generated is pCTP-URA. Bacillus subtilis alsS gene was amplified from the genomic DNA of B. subtilis using primers B.s.alsS-F-NotI and B.s.alsS-R-BglII. Meanwhile, E. aerogenes budA was amplified from the genomic DNA of $E$. aerogenes KCTC 2190 strain with primers E.a.budA-F-
BamHI and E.a.budA-R-Xhol. B. subtilis alsS and E. aerogenes budA fragment were cloned into pCTP-URA under the control of TEF1 promoter and PGK1 promoter, respectively.

In all cases, PCR was performed using TaKaRa LA Taq Polymerase with GC Buffer (Takara Bio Inc, Shiga, Japan). Yeast strains were transformed using the lithium acetate/PEG/SS-DNA method [49]. After transformation, successful transformants were selected on SC media without the appropriate amino acids.

\section{Batch fermentations}

For all fermentations, pre-cultures were prepared by inoculating $5 \mathrm{ml}$ of SC medium in a $50 \mathrm{ml}$ screw-capped tube with a fresh colony grown on solid medium. Batch fermentations were performed in $250 \mathrm{ml}$ Erlenmeyer flasks containing $50 \mathrm{ml}$ of synthetic complete dropout medium. Microaerobic condition was maintained in the flasks by sealing with rubber stoppers. For anaerobic fermentations, $50 \mathrm{ml}$ of SC medium supplemented with $0.42 \mathrm{~g} \cdot \mathrm{l}^{-1}$ Tween 80 and $0.01 \mathrm{~g} \cdot \mathrm{l}^{-1}$ cholesterol in a $150 \mathrm{ml}$ serum bottle was purged with pure nitrogen gas for 15 minutes to establish anaerobic condition. Initial $\mathrm{OD}_{660 \mathrm{~nm}}$ was adjusted at 0.05 . Fermentations were performed in shaking incubator at $30^{\circ} \mathrm{C}$, with agitation at $250 \mathrm{rpm}$.

\section{Analytical methods}

Cell growth was determined by measuring the absorbance at $660 \mathrm{~nm}$ using UV-VIS spectrophotometer (Shimazu UV mini 1240, Tokyo, Japan). In addition, we determined the dry cell mass of yeast at the end of shake-flask cultivation by filtering $30 \mathrm{ml}$ of culture through pre-weighed cellulose acetate membrane filters (Chmlab Group, Barcelona, Spain) with a pore size of $0.45 \mu \mathrm{m}$. Filters were dried at $65^{\circ} \mathrm{C}$ for 48 hours and weighed again. Then, we calculated the dry cell mass and estimated the cell biomass by using the dry cell mass/OD660 ratio at the end of cultivation.

For extracellular metabolite analysis, $1 \mathrm{ml}$ of culture samples were collected at appropriate time point. Isopropyl alcohol was added to the $1 \mathrm{ml}$-sample as internal standard and vortexed for $1 \mathrm{~min}$. The samples were then centrifuged (13500 rpm, $5 \mathrm{~min}$ ) and $200 \mu \mathrm{l}$ of supernatants were transferred to HPLC autosampler vials. Extracellular concentrations of glucose, glycerol, ethanol, acetate, succinate, acetoin and 2,3-butanediol were determined with a high performance liquid chromatography (HPLC) system (ACME-9000, Younglin Instrument, Seoul, South Korea) equipped with a refractive index detector (RID). Analytes were separated using Sugar SH1011 column (Shodex, Tokyo, Japan) with $10 \mathrm{mM}$ sulfuric acid as mobile phase pumped at $0.5 \mathrm{ml} \cdot \mathrm{min}^{-1}$. The column and the detector were set to $75^{\circ} \mathrm{C}$ and $45^{\circ} \mathrm{C}$, respectively. The order of elution was 
glucose, succinic acid, glycerol, acetate, acetoin, 2,3butanediol, ethanol and isopropyl alcohol. For quantitative analysis, standards for all metabolite at five different concentration levels were prepared. A calibration curve for each component was made and from these calibration curves concentrations of metabolites were calculated. The standard for 2,3-butanediol ( $\geq 99.0 \%$ (GC), Fluka Analytical, Sigma-Aldrich) and the extracellular 2,3-butanediol from the fermentation samples are a mixture of racemic and meso forms. Extracellular acetaldehyde concentrations were determined with Megazyme Acetaldehyde Assay Kit (Megazyme International Ireland, Wicklow, Ireland) according to the manufacturer's instructions.

\section{Additional files}

Additional file 1: Additional description for Table 1. (a) A list of the corresponding enzymes, reaction equations and subsystems for target reactions listed in Table 1 and (b) a figure showing the 2,3-butanediol production envelope of OptKnock strain A.

Additional file 2: Oligonucleotides used in this study. A list of oligonucleotides that were used in this study.

Additional file 3: Verification of gene deletion strains by colony PCR. The PCR profiles of wild-type and gene deletion strains.

\section{Abbrevation list}

FBA: flux balance analysis; PDH: pyruvate dehydrogenase; ADH: alcohol dehydrogenase; G3P: glycerol-3-phosphate.

\section{Competing interests}

The authors declare that they have no competing interests.

\section{Authors' contributions}

MKO and $J L$ conceived the study. MKO designed and supervised the study, and contributed to manuscript writing. CYN participated in the design of the study, performed the experiments and drafted the manuscript. MYJ helped to conduct HPLC analysis. All authors read and approved the final manuscript.

\section{Acknowledgements}

This research was financed by the Research \& Development Program of Ministry of Knowledge Economy (MKE) and Korea Evaluation Institute of Industrial Technology (KEIT) (No. 10035578, Development of 2,3-butanediol and derivative production technology for C-Zero bio-platform industry), Republic of Korea. We would also like to thank Tae-yeon Kim for constructing PTKURA3 plasmid.

\section{Author details}

'Department of Chemical \& Biological Engineering, Korea University, Seoul 136-701, Republic of Korea. ${ }^{2}$ Department of Chemical \& Biomolecular Engineering, Sogang University, Seoul 121-742, Republic of Korea.

Received: 13 December 2011 Accepted: 4 May 2012

Published: 28 May 2012

\section{References}

1. Ji X-J, Huang H, Ouyang P-K: Microbial 2,3-butanediol production: A stateof-the-art review. Biotechnol Adv 2011, 29:351-364.

2. Celinska E, Grajek W: Biotechnological production of 2,3-butanediolcurrent state and prospects. Biotechnol Adv 2009, 27:715-725.

3. Yang T, Rao Z, Zhang X, Lin Q, Xia H, Xu Z, Yang S: Production of 2,3butanediol from glucose by GRAS microorganism Bacillus amyloliquefaciens. J Basic Microbiol 2011, 51:650-658.
4. Chen GC, Jordan F: Brewers' yeast pyruvate decarboxylase produces acetoin from acetaldehyde: a novel tool to study the mechanism of steps subsequent to carbon dioxide loss. Biochemistry 1984, 23:3576-3582.

5. Sergienko EA, Jordan F: Catalytic acid-base groups in yeast pyruvate decarboxylase. 2. Insights into the specific roles of D28 and E477 from the rates and stereospecificity of formation of carboligase side products. Biochemistry 2001, 40:7369-7381.

6. Blomqvist K, Suihko ML, Knowles J, Penttila M: Chromosomal Integration and Expression of Two Bacterial alpha-Acetolactate Decarboxylase Genes in Brewer's Yeast. Appl Environ Microbiol 1991, 57:2796-2803.

7. Suihko ML, Blomqvist K, Penttila M, Gisler R, Knowles J: Recombinant brewer's yeast strains suitable for accelerated brewing. J Biotechnol 1990, 14:285-300.

8. Remize F, Roustan J, Sablayrolles J, Barre P, Dequin S: Glycerol overproduction by engineered Saccharomyces cerevisiae wine yeast strains leads to substantial changes in by-product formation and to a stimulation of fermentation rate in stationary phase. Appl Environ Microbiol 1999, 65:143.

9. Ehsani M, Fernandez MR, Biosca JA, Julien A, Dequin S: Engineering of 2,3butanediol dehydrogenase to reduce acetoin formation by glyceroloverproducing, low-alcohol Saccharomyces cerevisiae. Appl Environ Microbiol 2009, 75:3196-3205.

10. Romano P, Suzzi G: Origin and production of acetoin during wine yeast fermentation. Appl Environ Microbiol 1996, 62:309.

11. Lewis NE, Nagarajan $H$, Palsson BO: Constraining the metabolic genotypephenotype relationship using a phylogeny of in silico methods. Nat Rev Microbiol 2012, 10:291-305.

12. Forster J, Famili I, Fu P, Palsson BO, Nielsen J: Genome-scale reconstruction of the Saccharomyces cerevisiae metabolic network. Genome Res 2003, 13:244-253.

13. Mo ML, Palsson BO, Herrgard MJ: Connecting extracellular metabolomic measurements to intracellular flux states in yeast. BMC Syst Biol 2009, 3:37.

14. Herrgard MJ, Swainston N, Dobson P, Dunn WB, Arga KY, Arvas M, Bluthgen $\mathrm{N}$, Borger $\mathrm{S}$, Costenoble R, Heinemann $\mathrm{M}$, et al: A consensus yeast metabolic network reconstruction obtained from a community approach to systems biology. Nat Biotechnol 2008, 26:1155-1160.

15. Duarte NC, Herrgard MJ, Palsson BO: Reconstruction and validation of Saccharomyces cerevisiae iND750, a fully compartmentalized genomescale metabolic model. Genome Res 2004, 14:1298-1309.

16. Orth JD, Thiele I, Palsson BO: What is flux balance analysis? Nat Biotechnol 2010, 28:245-248.

17. Edwards JS, Covert M, Palsson B: Metabolic modelling of microbes: the flux-balance approach. Environ Microbiol 2002, 4:133-140.

18. Burgard AP, Pharkya P, Maranas CD: Optknock: a bilevel programming framework for identifying gene knockout strategies for microbial strain optimization. Biotechnol Bioeng 2003, 84:647-657.

19. Fong SS, Burgard AP, Herring CD, Knight EM, Blattner FR, Maranas CD, Palsson BO: In silico design and adaptive evolution of Escherichia coli for production of lactic acid. Biotechnol Bioeng 2005, 91:643-648.

20. Xu P, Ranganathan S, Fowler ZL, Maranas CD, Koffas MA: Genome-scale metabolic network modeling results in minimal interventions that cooperatively force carbon flux towards malonyl-CoA. Metab Eng 2011, 13:578-587.

21. Yim H, Haselbeck R, Niu W, Pujol-Baxley C, Burgard A, Boldt J, Khandurina J, Trawick JD, Osterhout RE, Stephen R, et al: Metabolic engineering of Escherichia coli for direct production of 1,4-butanediol. Nat Chem Biol 2011, 7:445-452.

22. Matsuda F, Furusawa C, Kondo T, Ishii J, Shimizu H, Kondo A: Engineering strategy of yeast metabolism for higher alcohol production. Microb Cell Fact 2011, 10:70.

23. Asadollahi MA, Maury J, Patil KR, Schalk M, Clark A, Nielsen J: Enhancing sesquiterpene production in Saccharomyces cerevisiae through in silico driven metabolic engineering. Metab Eng 2009, 11:328-334.

24. Schuster S, Pfeiffer T, Fell DA: Is maximization of molar yield in metabolic networks favoured by evolution? J Theor Biol 2008, 252:497-504.

25. Kennedy CJ, Boyle PM, Waks Z, Silver PA: Systems-level engineering of nonfermentative metabolism in yeast. Genetics 2009, 183:385.

26. Bro C, Regenberg B, Forster J, Nielsen J: In silico aided metabolic engineering of Saccharomyces cerevisiae for improved bioethanol production. Metab Eng 2006, 8:102-111. 
27. Pronk JT, Steensma HY, Van Dijken JP: Pyruvate metabolism in Saccharomyces cerevisiae. Yeast 1996, 12:1607-1633.

28. Nissen TL, Kielland-Brandt MC, Nielsen J, Villadsen J: Optimization of Ethanol Production in Saccharomyces cerevisiae by Metabolic Engineering of the Ammonium Assimilation. Metab Eng 2000, 2:69-77.

29. Bieganowski P, Seidle HF, Wojcik M, Brenner C: Synthetic lethal and biochemical analyses of NAD and NADH kinases in Saccharomyces cerevisiae establish separation of cellular functions. J Biol Chem 2006, 281:22439-22445.

30. Drewke C, Thielen J, Ciriacy M: Ethanol formation in adh0 mutants reveals the existence of a novel acetaldehyde-reducing activity in Saccharomyces cerevisiae. J Bacteriol 1990, 172:3909.

31. Dickinson JR, Salgado LE, Hewlins MJ: The catabolism of amino acids to long chain and complex alcohols in Saccharomyces cerevisiae. J Biol Chem 2003, 278:8028-8034

32. Weimer EP, Rao E, Brendel M: Molecular structure and genetic regulation of SFA, a gene responsible for resistance to formaldehyde in Saccharomyces cerevisiae, and characterization of its protein product. Mol Gen Genet MGG 1993, 237:351-358.

33. Smith MG, Des Etages SG, Snyder M: Microbial Synergy via an EthanolTriggered Pathway. Mol Cell Biol 2004, 24:3874-3884.

34. de Smidt O, du Preez JC, Albertyn J: Molecular and physiological aspects of alcohol dehydrogenases in the ethanol metabolism of Saccharomyces cerevisiae. FEMS Yeast Res 2012, 12:33-47.

35. Skory CD: Lactic acid production by Saccharomyces cerevisiae expressing a Rhizopus oryzae lactate dehydrogenase gene. J Ind Microbiol Biotechnol 2003, 30:22-27.

36. Stanley GA, Douglas NG, Every EJ, Tzanatos T, Pamment NB: Inhibition and stimulation of yeast growth by acetaldehyde. Biotechnol Lett 1993, 15:1199-1204

37. Tokuhiro K, Ishida N, Nagamori E, Saitoh S, Onishi T, Kondo A, Takahashi H: Double mutation of the PDC1 and ADH1 genes improves lactate production in the yeast Saccharomyces cerevisiae expressing the bovine lactate dehydrogenase gene. Appl Microbiol Biotechnol 2009, 82:883-890.

38. Eglinton JM, Heinrich AJ, Pollnitz AP, Langridge P, Henschke PA, de Barros Lopes M: Decreasing acetic acid accumulation by a glycerol overproducing strain of Saccharomyces cerevisiae by deleting the ALD6 aldehyde dehydrogenase gene. Yeast 2002, 19:295-301.

39. Ludovico P, Sousa MJ, Silva MT, Leão C, Côrte-Real M: Saccharomyces cerevisiae commits to a programmed cell death process in response to acetic acid. Microbiology 2001, 147:2409-2415.

40. Roustan J, Sablayrolles J: Impact of the addition of electron acceptors on the by-products of alcoholic fermentation. Enzym Microb Technol 2002, 31:142-152.

41. Ansell R, Granath K, Hohmann S, Thevelein JM, Adler L: The two isoenzymes for yeast NAD +-dependent glycerol 3-phosphate dehydrogenase encoded by GPD1 and GPD2 have distinct roles in osmoadaptation and redox regulation. EMBO J 1997, 16:2179-2187.

42. Gollop N, Damri B, Chipman D, Barak Z: Physiological implications of the substrate specificities of acetohydroxy acid synthases from varied organisms. J Bacteriol 1990, 172:3444-3449.

43. Carballo J, Martin R, Bernardo A, Gonzalez J: Purification, characterization and some properties of diacetyl(acetoin) reductase from Enterobacter aerogenes. Eur J Biochem 1991, 198:327-332.

44. Ehsani M, Fernandez MR, Biosca JA, Dequin S: Reversal of coenzyme specificity of 2,3-butanediol dehydrogenase from Saccharomyces cerevisae and in vivo functional analysis. Biotechnol Bioeng 2009, 104:381389

45. Wach A: PCR-synthesis of marker cassettes with long flanking homology regions for gene disruptions in S. cerevisiae. Yeast 1996, 12:259-265.

46. Mumberg D, Müller R, Funk M: Yeast vectors for the controlled expression of heterologous proteins in different genetic backgrounds. Gene 1995, 156:119-122.

47. Schellenberger J, Que R, Fleming RM, Thiele I, Orth JD, Feist AM, Zielinski DC, Bordbar A, Lewis NE, Rahmanian S, et al: Quantitative prediction of cellular metabolism with constraint-based models: the COBRA Toolbox v2.0. Nat Protoc 2011, 6:1290-1307.

48. Güldener U, Heck S, Fiedler T, Beinhauer J, Hegemann JH: A new efficient gene disruption cassette for repeated use in budding yeast. Nucleic Acids Res 1996, 24:2519.
49. Gietz RD, Schiestl RH, Willems AR, Woods RA: Studies on the transformation of intact yeast cells by the LiAc/SS-DNA/PEG procedure. Yeast 1995, 11:355-360.

doi:10.1186/1475-2859-11-68

Cite this article as: $\mathrm{Ng}$ et al:: Production of 2,3-butanediol in

Saccharomyces cerevisiae by in silico aided metabolic engineering.

Microbial Cell Factories 2012 11:68.

\section{Submit your next manuscript to BioMed Central and take full advantage of:}

- Convenient online submission

- Thorough peer review

- No space constraints or color figure charges

- Immediate publication on acceptance

- Inclusion in PubMed, CAS, Scopus and Google Scholar

- Research which is freely available for redistribution 